\title{
Time to connect
}

\author{
Researchers who use genetically modified primates need to gear up for the inevitable public debate.
}

$\int$ apanese researchers announce a major accomplishment in this issue of Nature: the creation of the first transgenic primates able to pass on a foreign gene to their offspring (see pages 492, 515 and 523). Because the primates in question are marmoset monkeys that are distant from humans in an evolutionary sense, this experiment has little immediate bearing on the modification of human germ lines - a prospect that many people find unacceptable in any case. But the advance will lead to more sophisticated models for human disease, physiological development and neurogenetics. And in so doing, it will inevitably draw more attention from animal-rights activists.

Posters that feature an endearing marmoset face peering out of a cage and a caption denouncing experiments will make for an emotionally appealing campaign. Granted, the transgenic marmosets presented this week have been equipped with a simple green fluorescent protein; the only thing that they seem to do differently from normal monkeys is glow. But experiments such as these are headed in a new direction. The study of human diseases will require engineered marmosets that are born with and live their entire lives with a genetic defect that they pass on to their progeny. And this prospect - intentionally introducing a harmful gene into the primate gene pool - promises to raise the stakes in the long-standing controversy over animal rights.

Nature believes that such experiments are justified by the value of the research, as long as they are carried out in a responsible fashion. But researchers must be ready to deal with the broader ethical questions involved. If unprepared, they risk being caught wrong-footed when the debate inevitably takes off.

Although Japan is poised to become a leader in this field of primate transgenics, its researchers seem less than ready to take on the bioethical challenge. Japanese researchers and policy-makers have tried to answer concerns about animal rights by introducing animal-experimentation guidelines and by holding public symposia to expound the value of the research. But these initiatives, although worthwhile, are inadequate when public and political sympathy can so easily be influenced by opponents.
Animal research in Japan and its supporters should heed the lessons from the West, where researchers have won several political victories by addressing the issues openly. For example, during last year's debates over hybrid embryo research in the United Kingdom, scientists publicly demonstrated an acute awareness of the ethical aspects of research practice and of the potential applications, showing respect for opposing ethical positions yet rapidly rebutting misrepresentations about the research. This forward-looking and transparent approach won public and political support at the crucial moments at which regulation was being formulated.

Following that model will not be easy for Japanese scientists, who freely admit their dislike for public confrontation. Although they have not yet had to face the kind of violence and intimidation that is sometimes practised by animal-rights activists in Europe and the United States, researchers in Japan generally shy away from presenting
"The lesson for the animal-rights debate is that more engagement, not less, is the best way to promote the research." details of what they do. But if they do not actively seek a positive solution to promoting their research, they run the risk of an adverse one being reached - quite possibly in a bureaucratic back room in which flummoxed officials are under pressure from anti-research activists. In embryonic-stem-cell research, for example, Japanese researchers won an ostensibly lax legal framework, but critics were able to force the inclusion of laborious regulations that crippled the stem-cell community for years (see Nature 438, 263; 2005). Primate researchers in continental Europe have also been caught off guard by behind-the-scenes negotiations (see Nature 444, 812-813; 2006).

The lesson for the animal-rights debate is that more engagement, not less, is the best way to promote the research. Scientists everywhere must be ready to discuss animal welfare, the possibility of transgenic humans and other controversial topics, based on a thorough understanding of the ethical issues and a capacity to respond rapidly in public.

central team cannot visit it without an escort. The site is under the tight control of the CEA, the French Atomic Energy Commission.

This is the realpolitik of the planet's most expensive science experiment. In 2006, when ITER was approved by the European Union, China, India, Japan, Russia, South Korea and the United States, the members were careful to ensure that their own agencies had strong influence on the project. Through ITER's governing council, domestic nuclear agencies have ultimate control over everything from the appointment of the central organization's senior staff to the project's scope and schedule. The same agencies will be the ones letting contracts to industry and overseeing production of most of the parts for the machine. lies a roughly one-kilometre by half-kilometre earthen platform on which the fusion reactor will be constructed. Yet members of ITER's 